\title{
Passive samplers to quantify micropollutants in sewer overflows: accumulation behaviour and field validation for short pollution events
}

Mutzner Lena ${ }^{1,2}$, Vermeirssen Etiënne L.M. ${ }^{3}$, Mangold Simon ${ }^{1}$, Maurer Max ${ }^{1,2}$, Scheidegger Andreas ${ }^{1}$, Singer Heinz ${ }^{1}$, Booij Kees ${ }^{4}$, Ort Christoph ${ }^{1 *}$

1 Eawag, Swiss Federal Institute of Aquatic Science and Technology, 8600 Dübendorf, Switzerland.

2 Institute of Civil, Environmental and Geomatic Engineering, ETH Zürich, 8093 Zurich, Switzerland.

3 Swiss Centre for Applied Ecotoxicology, 8600 Dübendorf, Switzerland

4 Passive Sampling of Organic Compounds (PaSOC), 8821LV Kimswerd, The Netherlands

*Christoph.ort@eawag.ch

\section{Graphical Abstract}

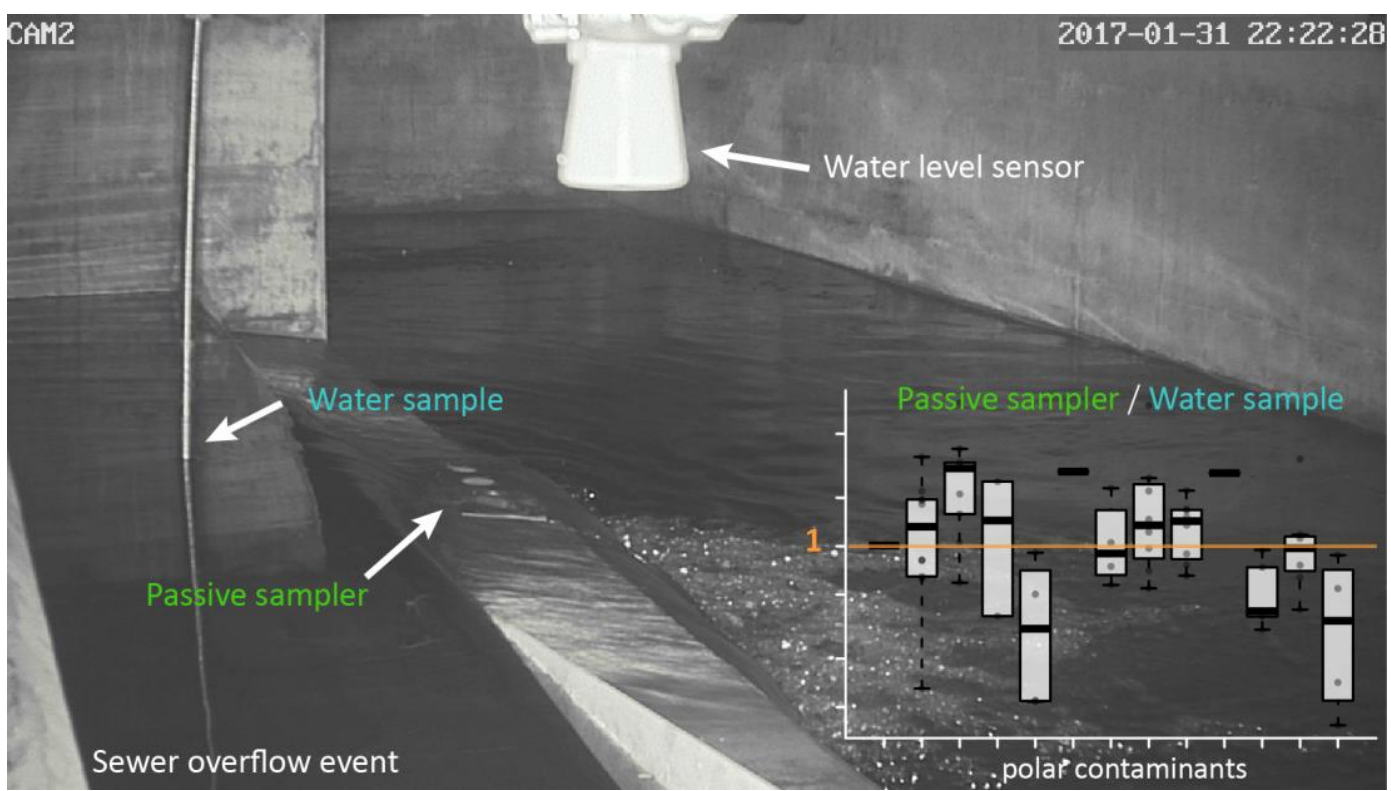

This document is the accepted manuscript version of the following article:

Mutzner, L., Vermeirssen, E. L. M., Mangold, S., Maurer, M., Scheidegger, A., Singer, H., ... Ort, C. (2019). Passive samplers to quantify micropollutants in sewer overflows: accumulation behaviour and field validation for short pollution events. Water Research, 160, 350-360. https://doi.org/10.1016/j.watres. 2019.04.012

This manuscript version is made available under the CC-BY-NC-ND 4.0 1icense http:// creativecommons.org/1icenses/by-nc-nd/4.0/ 


\begin{abstract}
Contaminants in sewer overflows can contribute to exceedances of environmental quality standards, thus the quantification of contaminants during rainfall events is of relevance. However, monitoring is challenged by i) high spatiotemporal variability of contaminants in events of hard-to-predict durations, and ii) a large number of remote sites, which would imply enormous efforts with traditional sampling equipment. Therefore, we evaluate the applicability of passive samplers (Empore styrenedivinylbenzene reverse phase sulfonated (SDB-RPS)) to monitor a set of 13 polar organic contaminants. We present calibration experiments at high temporal resolution to assess the rate limiting accumulation mechanisms for short events $(<36 \mathrm{~h})$, report parameters for typical sewer conditions and compare passive samplers with composite water samples in a field study (three locations, total 10 events). With sampling rates of 0.35 to $3.5 \mathrm{~L} / \mathrm{d}$ for one hour reference time, our calibration results indicate a high sensitivity of passive samplers to sample short, highly variable sewer overflows. The contaminant uptake kinetic shows a fast initial accumulation, which is not well represented with the typical first-order model. Our results indicate that mass transfer to passive samplers is either controlled by the water boundary layer and the sorbent, or by the sorbent alone. Overall, passive sampler concentration estimates are within a factor 0.4 to 3.1 in comparison to composite water samples in the field study. We conclude that passive samplers are a promising approach to monitor a large number of discharge sites although it cannot replace traditional stormwater quality sampling in some cases (e.g. exact load estimates, high temporal resolution). Passive samplers facilitate identifying and prioritizing locations that may require more detailed investigations.
\end{abstract}

\title{
Keywords
}

polar organic pollutant; Chemcatcher; monitoring; pesticide, pharmaceutical

\section{Abbreviations}

PS

WS

EQS

LOQ

$\mathrm{C}$

$\mathrm{C}(\mathrm{t})$

TWA

$\mathrm{M}_{\mathrm{PS}}$

$\mathrm{C}_{\mathrm{PS}}$

$\mathrm{C}_{\text {Comp.Sample }}$

SDB-RPS

POCIS
Passive sampler

Water sample

Environmental quality standard

Limit of quantification

Concentration of contaminant in the water

Concentration of contaminant at time point $t$

Time-weighted average

Mass of contaminant measured on passive sampler

$\mathrm{C}_{\mathrm{TWA}}$ calculated from $\mathrm{M}_{\mathrm{PS}}$

$\mathrm{C}_{\mathrm{TWA}}$ in a composite sample (grab samples combined over a specific sampling period)

Styrene-divinylbenzene reverse phase sulfonated

Polar organic chemical integrative sampler 


\section{Introduction}

In case of rain events, untreated wastewater and stormwater may be discharged via sewer overflows to creeks and lakes, when the hydraulic capacity of either wastewater treatment plant or of sewer system locally is exceeded. These discharge events can negatively impact natural aquatic environments since organic pollutant concentrations may exceed environmental quality standards (Launay et al. 2016; Mutzner et al. 2016; Risch et al. 2018; Brudler et al. 2019). In stormwater, the occurrence of polar organic pollutants (pharmaceuticals, pesticides subsequent referred to as contaminants) depends strongly on local factors, including land use, substance application, rain fall intensity and duration, as well as dry periods between storms. This high spatiotemporal variability was shown in a number of recent studies (Zgheib et al. 2011; Wicke et al. 2014; Becouze-Lareure et al. 2015; Rippy et al. 2017; Burant et al. 2018; Fairbairn et al. 2018). This variability challenges an efficient monitoring in combination with a large number of sewer overflow sites.

One promising option to overcome these challenges is passive sampling, where accumulation of contaminants is based on the concentration difference between the receiving passive sampler sorbent and the water phase. The rate limiting step for contaminant accumulation can be diffusion through i) the water boundary layer, ii) biofilms, iii) membranes and iv) the sampler sorbent (Huckins et al. 2006; Booij et al. 2007). Thus, accumulation on passive samplers depend on contaminant properties, matrix of sampled water and environmental conditions for which passive samplers need to be calibrated before exposure. This calibration in combination with knowledge of the accumulation mechanisms of passive samplers allows the estimation of time-weighted average (TWA) water concentrations. However, the mechanisms of accumulation and desorption of polar contaminants into passive samplers are still not fully understood (Miège et al. 2015), particularly for short durations (<1d). To date, contaminant concentrations in sewer overflows have mainly been monitored with traditional sampling methods such as grab samples and auto-samplers which have their short-comings. Grab samples collected at a few time points are likely to not properly cover the high fluctuations of rain-driven wet-weather discharges (Ort et al. 2010). Water collection with auto-samplers is logistically and financially very costly (Alvarez et al. 2005; Vrana et al. 2005) and, therefore, covering a high number of sewer overflow sites is often not possible. TWA concentrations are not sufficient to estimate contaminant loads in case of highly fluctuating concentrations and flows. Nevertheless it is often beneficial to have TWA concentration information instead no information.

The Chemcatcher® sampler (Kingston et al. 2000) is one of two common designs used to sample polar organic contaminants (Miège et al. 2015). For the monitoring of short duration pollution events, Shaw and Mueller (2009) suggested the use of styrenedivinylbenzene reverse phase sulfonated disks (SDBRPS) without polyethersulfone (PES) membrane to obtain a high mass uptake of the passive samplers. As no biofilm build-up is expected for short exposures (minutes to hours), the contaminant mass transfer in sewer overflow is assumed to be limited by the water boundary layer or the sampler sorbent. Previous calibration studies with SDB-RPS disks and polar organic pollutants were conducted at flow velocities $<0.2 \mathrm{~m} / \mathrm{s}$ (Stephens et al. 2005; Stephens et al. 2009; Vermeirssen et al. 2013). However, flow velocities in sewer systems can be higher and, contaminant accumulation may not be water boundary layer controlled at higher flow velocities (Green and Abraham 2000; Booij and Chen 2018).

Recent studies have shown, that passive samplers accumulate polar organic contaminants in wastewater treatment plant influent and effluents over periods of days (Vermeirssen et al. 2009; Harman et al. 2011; Petrie et al. 2016; Skodova et al. 2016; Baz-Lomba et al. 2017). Another study monitored heavy metals in a storm sewer with a flow-through passive sampler (Birch et al. 2013). 
Results show a good agreement of passive sampling results with volume-proportionally pooled samples. In addition, our previous findings showed that passive samplers are suitable for sampling fluctuating concentrations (Mutzner et al. 2019). These results indicate that passive samplers could be used to monitor highly variable, short duration storm events in sewer overflows. However, very limited experimental and field performance data are available so far.

Therefore, the motivation of our study is to systematically determine the applicability of passive samplers to monitor polar organic contaminants in short (minutes to hours), highly variable (event duration and concentration fluctuations) sewer overflows. We aim to understand accumulation mechanisms and to report calibration parameters for sewer conditions to enable future monitoring studies. The three main questions of this study are:

i. Are contaminant concentrations in the range of environmental quality standards quantifiable in relatively short, highly variable events?

ii. What model is suitable to describe the accumulation mechanism on passive samplers for short exposures?

iii. How do time-weighted average concentration estimates in discharge events from passive samplers compare to concentrations measured in traditionally collected composite water samples (field validation)?

\section{Theory}

\subsection{First-order accumulation kinetics}

A first-order differential equation is often used to describe the uptake of contaminant mass $M_{P S}$ [ng] on passive samplers. The change of the contaminant mass is described as

$\frac{d M_{P S}}{d t}=R_{S}\left(C(t)-\frac{M_{P S}}{m \cdot K_{S W}}\right)$

where the concentration in the water phase at time point $t$ [d] is denoted $C(t), m$ represents passive sampler mass (Empore, SDB-RPS; $332 \times 10^{-6} \mathrm{~kg}$ ), $R_{S}[\mathrm{~L} / \mathrm{d}]$ the sampling rate, and $K_{S W}$ the sampler-water distribution coefficient $[\mathrm{L} / \mathrm{kg}]$. Eq. 1 describes the contaminant mass flux as linearly proportional to the concentration difference between water and sorbent. Under the assumption that the concentration in the water phase is constant over time, i.e. $C(t)=C$, the solution of Eq. 1 is:

$M_{P S}(t)=C m K_{S W}\left(1-e^{-\frac{R_{S} \cdot t}{m \cdot K_{S W}}}\right)$

For small $t$ the above Eq. 2 approaches:

$M_{P S}(t)=R_{S} \cdot C \cdot t$

This approximation is typically considered valid for exposure durations smaller than $t_{1 / 2}=$ $\frac{m \cdot K_{S W}}{R_{S}} \ln (2)$.

\subsection{Sorbent controlled kinetics}

The first-order model of Eq. 1 is valid if the flux of contaminant is controlled by the water boundary layer (Stephens et al. 2005; Belles et al. 2014). However, if the flux is sorbent controlled instead, the mass transfer for short time limits can be described by diffusion into a semi-infinite medium (Eq. 3.15 in Crank 1975), as 
$M_{P S}=2 \cdot C \cdot K_{S W} \cdot \rho \cdot\left(\frac{D t}{\pi}\right)^{\frac{1}{2}}$

Where $D$ is the the diffusion coefficient and the density of the sorbent $\rho$. For intermediate cases between water boundary layer and sorbent controlled uptake, Belles et al. (2014) suggested a semiempirical model for the passive sampler Nylon-POCIS (Polar organic chemical integrative sampler). A slightly adapted version of this semi-empirical model can be used to describe mixed rate controlled uptake as follows

$M_{P S}=k \cdot m \cdot C \cdot t^{n}$

where $\mathrm{k}[\mathrm{L} / \mathrm{kg} / \mathrm{hn}]$ is the rate constant and $\mathrm{n}$ allows identifying rate controlling transport steps (Belles et al. 2014; Tran et al. 2017). If $n$ is estimated to be close to 0.5 the transport is governed by the sorbent (Eq. 4). For $\mathrm{n}$ close to 1, the transport process follows the water boundary layer controlled model of Eq. 1. For $n$ between 0.5 and 1 the mass uptake on the passive sampler is a mixed rate controlled uptake. An exact model for the case of mixed rate control by the sorbent and the water boundary layer is given by Crank (1975, Eq. 4.53). Because this model is computationally quite demanding, we prefer to use the semi-empirical Eq. 5, with $0.5<\mathrm{n}<1$. It must be noted, however, that Eq. 5 can only be applied in the short time limit, because $n$ decreases with time as equilibrium is gradually attained (i.e., $\mathrm{n}=0$ at equilibrium).

\section{Material and methods}

\subsection{Passive sampler calibration for short exposures in wastewater}

Two calibration experiments were conducted to assess the sorption accumulation behaviour of passive samplers during short exposures in a groundwater-wastewater mixture to mimic a stormwater matrix (Figure 1). Passive samplers (Empore, SDB-RPS disks, $47 \mathrm{~mm}$ diameter, $0.5 \mathrm{~mm}$ thickness, total disk surface area of $17.3 \mathrm{~cm}^{2}$ ) were exposed in raw wastewater in a flow channel (Experiment I, II) with flow direction parallel to the exposed disk (Figure SI 1). Duplicates of pre-conditioned passive samplers were exposed for time intervals of minutes to $36 \mathrm{~h}$. The passive samplers were mounted between stainless steel plates with a one-sided exposed surface area of $12.6 \mathrm{~cm}^{2}$ circular opening as detailed in Vermeirssen et al. (2013).

\begin{tabular}{|c|c|c|c|c|c|c|c|c|c|c|c|c|c|c|c|c|}
\hline \multirow[t]{2}{*}{ Matrix } & \multirow[t]{2}{*}{ Sample } & \multicolumn{15}{|c|}{ Retrival Time [min] } \\
\hline & & 0 & 5 & 15 & 30 & 60 & 120 & 180 & 240 & 300 & 420 & 480 & 840 & 1440 & 1800 & 2160 \\
\hline \multicolumn{17}{|c|}{ Experiment $\mathrm{I}: \mathrm{v}=0.75-0.80 \mathrm{~m} / \mathrm{s}, T=17.9( \pm 0.8)^{\circ} \mathrm{C}, \mathrm{pH}=8.3( \pm 0.1)$} \\
\hline \multirow{2}{*}{$100 \%$ wastewater } & PS & $*$ & & & & & $\mathbf{x}$ & $\mathbf{x}$ & & $\mathbf{x}$ & $\mathbf{x}$ & & & & & \\
\hline & WS & $\mathbf{x}$ & & & & & $\mathbf{x}$ & & & $\mathbf{x}$ & $\mathbf{x}$ & & & & & \\
\hline \multicolumn{17}{|c|}{ Experiment II: $v=0.78-0.85 \mathrm{~m} / \mathrm{s}, T=15.6^{\circ} \mathrm{C}( \pm 0.4), p H=8.0( \pm 0.2)$} \\
\hline \multirow{2}{*}{$\begin{array}{l}20 \% \text { wastewater } \\
80 \% \text { groundwater }\end{array}$} & PS & $*$ & $\mathbf{x}$ & $\mathbf{x}$ & $\mathbf{x}$ & $\mathbf{x}$ & $\mathbf{x}$ & & $\mathbf{x}$ & & & $\mathbf{x}$ & $\mathbf{x}$ & $\mathbf{x}$ & $\mathbf{x}$ & $\mathbf{x}$ \\
\hline & WS & $\mathbf{x}$ & & & $\mathbf{x}$ & $\mathbf{x}$ & & & $\mathbf{x}$ & & & $\mathbf{x}$ & $\mathbf{x}$ & $\mathbf{x}$ & $\mathbf{x}$ & $\mathbf{x}$ \\
\hline
\end{tabular}

Figure 1. Overview on passive sampler accumulation Experiment I and II with the mean ( \pm standard deviation) of flow velocity v, temperature $\mathrm{T}$ and $\mathrm{pH}$. All Samplers were exposed at time point $0 . \mathrm{x}$ : removal of duplicate passive samplers (PS) and 100mL water samples (WS), *duplicate experimental controls (not exposed)

Flow velocity, temperature (US TMC 20-HD, 1 min resolution) and pH (WTW Multi 3320, every $30 \mathrm{~min}$ ) were measured throughout all experiments and remained constant over the course of the individual experiments (Figure 1) The flow velocity was measured manually at the sampler surface with a handheld magnetic-inductive meter (OTT MF pro). In addition, duplicate experimental control 
passive samplers were treated the same way as the others samplers (preparation, mounting, transport, handling at the experimental site) but without exposure in the flow channel before extraction.

\subsubsection{Experiments on accumulation behaviour during short exposures}

The flow channel (length: $340 \mathrm{~cm}$, width: $6 \mathrm{~cm}$, water level: $11 \mathrm{~cm}$ ) was supplied with raw wastewater from a close by sewer and operated in batch mode by recirculating raw wastewater from a well-mixed $750 \mathrm{~L}$ tank. Before the start of the experiments, $100 \mathrm{~mL}$ wastewater sample was taken to assess the background contaminant concentration. At the beginning of the experiments, 13 contaminants were spiked to the tank with a target concentration of 2,000 ng/L (Table 1 for list of contaminants). Then passive samplers were installed in duplicates in the middle of the flow channel (Figure SI 12).

Experiment I was conducted with $100 \%$ wastewater pumped from a close by sewer and passive samplers were exposed for different time intervals up to seven hours. In Experiment I, we also assessed the effect of keeping passive samplers dry before and/or after exposure. This aspect was looked at because the objective was to install passive samplers in advance of the occurrence of a discharge event. Therefore, duplicate pre-conditioned passive samplers were kept in dry conditions in the sewer system for one and two weeks before being exposed in the flow channel. Also, duplicate passive samplers were stored in background wastewater for five hours or kept dry for five hours after exposure (SI section A).

In Experiment II passive samplers were exposed in the flow channel in shorter time intervals to assess the uptake behaviour in the first two hours. Experiment II also served to cover a longer exposure duration of $36 \mathrm{~h}$. $20 \%$ wastewater was pumped from a close by sewer and diluted with groundwater to mimic stormwater conditions. The real ratio of wastewater to groundwater in stormwater is highly variable due to variations in rainfall intensities and wastewater flow amounts.

\subsubsection{Parameter estimation for calibration experiments}

For the first-order model the parameters $R_{S}$ and $K_{S W}$ were estimated for Experiment II and both experiments (I and II) simultaneously with Bayesian inference. To account for fluctuating water concentrations during the calibration experiments (section 3.1) the differential equation Eq. 1 was solved numerically using the R package deSolve (Soetaert et al. 2010). For parameter estimation of the mixed rate control model, the TWA concentration $\mathrm{C}_{\text {Comp.Sample }}$ over the experiments was used in Eq. 5 . The parameters $k$ and $n$ were estimated for Experiment II as well as both flow channel experiments (I and II) simultaneously with Bayesian inference (Table SI 1 for parameter priors). An additive normal distributed error was assumed and uniform priors for the parameters. As the data systematically deviates for the first-order model also the selection relative error would not lead to a better model fit over the whole time (section 4.1). The inference was performed with the $\mathrm{R}$ package adaptMCMC (Scheidegger 2018) in R version 3.4.3 (R Core Team 2017). Four Markov chain Monte Carlo chains of length 20,000 were calculated for parameters inference as well as the confidence and prediction intervals. The data of Experiment I and II with the R code for parameter estimation with mixed rate control and first-order model is available under https://doi.org/10.25678/0000CC.

\subsection{Field study: comparability of passive and composite water samples}

The field study was conducted at three locations in different sewer systems as described in Mutzner et al. (2019). An auto-sampler and passive samplers were used simultaneously at each location to compare results. At location 1, we sampled in a sewer pipe (measured flow velocity $1.0-1.4 \mathrm{~m} / \mathrm{s}$, Flo- 
Dar 4000SR). At location 2, we sampled in a sewer overflow at the overflow weir (calculated flow velocity based on water level and weir crest formula by Poleni is approximately $0.75 \mathrm{~m} / \mathrm{s}$ ). Location 3 was a sewer by-pass (flow channel, section 3.1) in our experimental hall with a constant flow of wastewater (measured flow velocity $0.8 \mathrm{~m} / \mathrm{s}$, manually with OTT MF pro). Location 3 was also where the sampler uptake calibration Experiments I and II were performed (section 3.1). Water samples were taken every $5 \mathrm{~min}$, pooling four samples to a $20 \mathrm{~min}$ composite sample in a glass bottle (total 24 bottles). These single composite samples were combined to give the TWA concentration $\mathrm{C}_{\text {Comp.Sample }}$ over the sampled storm event. In total ten events with duration of $0.9 \mathrm{~h}$ to $18 \mathrm{~h}$ were monitored with $2-4$ replicate passive samplers in comparison to composite water samples (Table SI 3). The TWA concentration $\mathrm{C}_{\mathrm{PS}}$ in the event is calculated based on the measured mass MPS using the mixed rate control model (Eq. 5). The parameter values $\mathrm{k}$ and $\mathrm{n}$ are based on 50\%-quantile parameter estimate of the calibration Experiments I and II.

\subsubsection{Passive sampler installation in sewer systems}

Pre-conditioned, replicate passive samplers were exposed for the duration of the storm events, and 13 contaminants were studied (Table 1). In addition, field control passive samplers were treated the same way as the others samplers (preparation, mounting, transport, handling at the field) but without exposure before extraction. Preliminary assessments in calibration Experiment I showed that the passive samplers have to be kept in wet condition prior to exposure (Figure SI 3). Thus, we designed the mounting plates to be installed horizontally to keep passive samplers wetted with nanopure water before the storm event (Figure 2, technical dimensions in Figure SI 12). The passive samplers were fixed with the same stainless steel plates (one-sided opening of $12.6 \mathrm{~cm}^{2}$ ) as used for the calibration experiments (Figure 2B and section 3.1). In location 1, the mounting plate was installed $10 \mathrm{~cm}$ above the dry weather wastewater flow in the sewer to sample stormwater runoff (Figure SI 9). At location 2, the mounting plate was installed directly on the weir crest (Figure 2A). At location 3, the sampler holder was stored in nanopure water until the start of the storm event and was then installed manually on the wall of the flow channel (Figure SI 12: vertically, locations 1 and 2 horizontally).

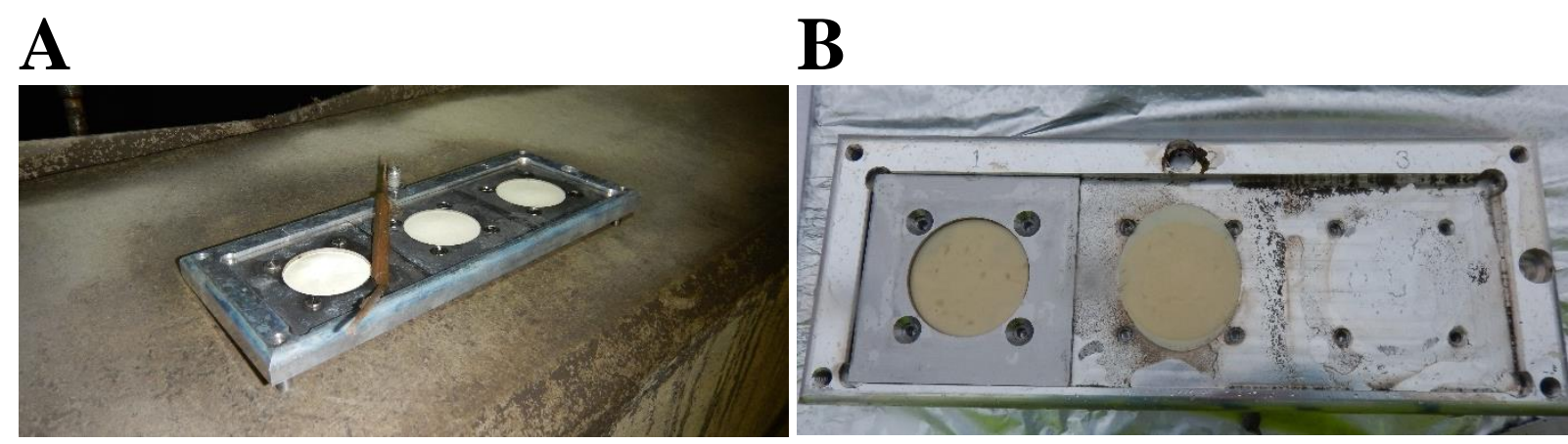

Figure 2.A. Installation of passive sampler holder with triplicate SDB-RPS disks on sewer overflow weir crest (location 2). B. Mounting plate and passive sampler disks after exposure in sewer overflow, left: with cover plate, middle: cover plate removed, right: cover plate and passive sampler removed.

\subsection{Sample preparation, extraction and analysis}

\subsubsection{Passive sampler preparation and extraction}

Before being exposed, Empore SDB-RPS disks were preconditioned in methanol (LC/MS grade, Optima $^{\mathrm{TM}}$, Fisher Scientific, Switzerland) and in nanopure water (Vermeirssen et al. 2009). After exposure, the whole disks were extracted with acetone and then methanol (both LC/MS grade, 
Optima $^{\mathrm{TM}}$, Fisher Scientific, Switzerland) as described in Vermeirssen et al. (2013). Structure-identical isotope-labelled standards ( $>98 \%$ purity) were added directly after shaking the disks with acetone on the rotary shaker to also account for possible analyte loss during sample preparation steps such as filtration and transfer by pipettes. Extracts from the calibration Experiment I and II were evaporated to ca. $0.1 \mathrm{~mL}$ and filled with nanopoure water to $1 \mathrm{~mL}$, extracts from the field study were evaporated to ca. $0.05 \mathrm{~mL}$ and filled with nanopure water to $0.5 \mathrm{~mL}$.

\subsubsection{Investigated contaminants}

The contaminants were selected based on the following criteria (Table 1 for list of contaminants): i) representative for a specific urban source, ii) previously reported in stormwater and wastewater in sufficient quantities, iii) polar organic contaminants with main transport in water phase $(\operatorname{logKow}<4)$, iii) ecotoxicologically relevant for the aquatic environment.

\subsubsection{Chemical analysis}

All passive and water samples were stored at $-20^{\circ} \mathrm{C}$ until analysis. The samples were measured with high performance liquid chromatography coupled to tandem mass spectrometry systems (high resolution and triple quadrupole) using electrospray as ionization source (HPLC-ESI-HRMS/MS) with the method described in Huntscha et al. (2012). Quantification was done via target screening using reference standards for each contaminant and isotope-labeled internal standards (ISTD). Twelve of the 13 investigated contaminants had their own, structure identical isotope labeled standard, only 1,3benzothiazole-2-sulfonic acid was quantified with a structure non identical ISTD (benzotriazole-d4) and, therefore, corrected by relative recovery. Quality controls were measured during all measurement sequences. An external reference standard mix showed relative recoveries of 80-120\%, spiked samples from 70-130\% for most compounds (except clarithromycin, diazinon and 1,3-benzothiazole2-sulfonic-acid, which showed slightly elevated relative recoveries). Blind controls (field blind, filter blind) did not show detects for most compounds. If compounds were detected in blind controls (e. g. benzotriazole), the LOQ (limit of quantification) was increased to at least three times the highest detected blind concentration. Further details on chemical analysis are given in SI Section C.

\section{Results and discussion}

\subsection{Passive sampler calibration for short exposures in wastewater}

The water concentrations remained relatively constant throughout the calibration experiments for most contaminants with coefficients of variations (CV) below 10\% (Figure SI 6). Clarithromycin showed a decreasing water concentration during both experiments and diazinon showed a decreasing water concentration in Experiment II. This decrease is assumed to be due to degradation during the recirculation in the flow channel, for wastewater treatment plants the removal was reported $50 \%$ for diazinon (Singer et al. 2010) and 70\% for clarithromycin (Senta et al. 2013). Carbamazepine had a concentration increase over time in both experiments. Possible explanations for this increase could be remobilization from particles or back-transformation from metabolites (Bahlmann et al. 2014; Launay et al. 2016).

\subsubsection{Accumulation does not follow first-order kinetics}

The first-order model (Eq. 1) poorly described the fast initial accumulation (burst), as shown for metolachlor and carbendazim in Figure 3A. This fast initial accumulation leads to detection of all 
contaminants after five minutes with accumulated mass between 3.3ng/disk (clarithromycin) and 35ng/disk (benzotriazole). The first-order model systematically underestimated the accumulated mass in the initial exposure hours and the duration of this underestimation depends on the overall time chosen for the model fit (Figure 3C, Figure SI 5 shows first-order model fit for 8h). As a result, application of the model to samplers exposed for $1 \mathrm{~h}$ lead to an overestimation of the water concentration by a factor 2 (mean over all contaminants). In addition, $K_{S W}$ are most likely higher than predicted, as the first-order model interprets a decrease in uptake as a sign of equilibration, but this could be also interpreted as increasing resistance of the sorbent.

As can be seen from Figure $3 \mathrm{~A}+\mathrm{C}$, the accumulation behaviour does not follow first-order kinetics in the first exposure hours. Therefore, the contaminant mass transfer seems to not be limited by the water boundary layer. The water boundary layer thickness depends on the hydrodynamics (Green and Abraham 2000; Vermeirssen et al. 2008; Booij and Chen 2018). In the flow channel experiments the flow velocities were higher than in previous studies and, thus the resistance of water boundary layer played less of a role for uptake. A similar fast initial accumulation over longer time scales (e.g. one day) was observed in previous studies for polar contaminants for POCIS (Mazzella et al. 2007; Belles et al. 2014; Fauvelle et al. 2014) and for SDB-RPS disks (Shaw et al. 2009; Vermeirssen et al. 2013).

\subsubsection{Mixed water boundary-sorbent controlled kinetics}

In one study the observed fast initial accumulation is attributed to sorbent-control as the limiting transport process (Belles et al. 2014). If the uptake kinetic is sorbent controlled, the accumulated mass is expected to be proportional to the square root of time, thus $n=0.5$ in Eq. 5. The application of the mixed rate control model is shown for metolachlor and carbendazim in Figure 3B (all contaminants in Figure SI 6). The mixed rate control model gives a better description of the data than the first order model, because the residual errors are smaller and more homogeneously distributed (Figure 3C $+\mathrm{D}$ ). As a result, both contaminants show an improved model fit of the fast initial accumulation, which indicates that sorbent control might play a role, especially for carbendazim with $n=0.55$ (Figure 3D) Contaminants with higher $\mathrm{n}$ values show a better fit for the traditional first-order model, as for example for metolachlor with $n=0.7$ (Figure $3 A+B$ ).

The contaminant specific $n$ ranges from 0.43 to 0.71 with a mean of 0.59 (Table 1). Therefore, for contaminants with $0.5<n<1$ the transport process seems controlled by a multi-step mechanism with water boundary layer diffusion and sorbent diffusion. The TWA water concentration estimate for short exposures were substantially improved by using the mixed rate control model with $\mathrm{t}^{\mathrm{n}}($ Eq. 5). For further usage for sewer overflows this model was fitted for both Experiment I and II simultaneously, resulting in $n=0.52$ to 0.88 with a mean of 0.67 (Table 1, Figure SI 6). However, this model does not take into account that accumulation rates decrease over time when equilibrium is gradually approached. Thus, the mixed rate control model would need to be adopted for longer exposure durations by taking into account mixed diffusion accumulation (Crank 1975). 

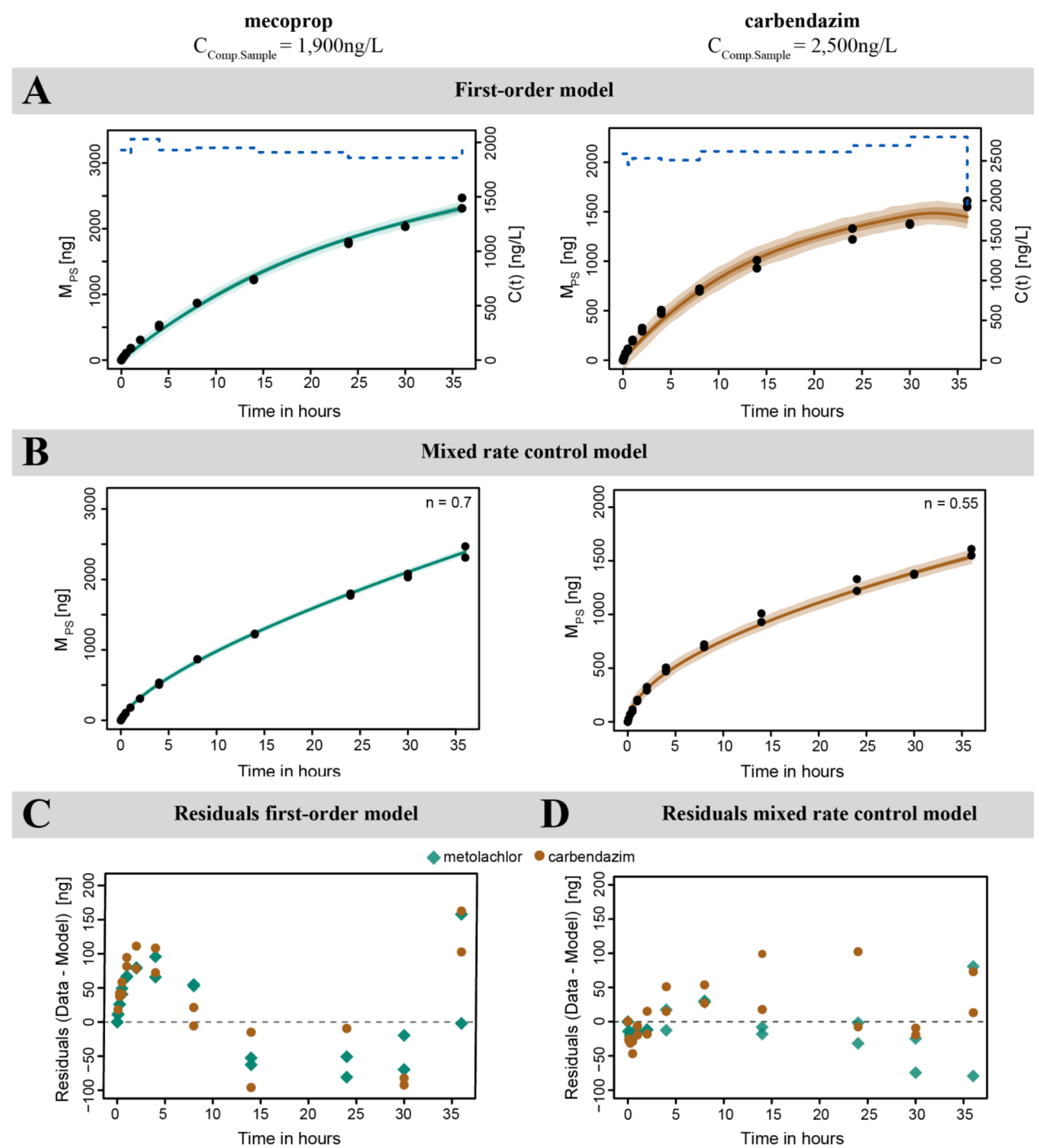

Residuals mixed rate control model

Figure 3.Accumulation for metolachlor and carbendazim for calibration Experiment II. Measured mass $\mathrm{M}_{\mathrm{PS}}$ on duplicate passive sampler (points) and modelled uptake behaviour (solid line). Dashed, blue line: water concentration $\mathrm{C}(\mathrm{t})$, dark shaded bands: 80\%-confidence intervals, light shaded bands: 80\%-prediction intervals. Model parameter estimates are fitted or Experiment II only to show accumulation mechanisms. A. First-order model (Eq. 1) based on parameter estimates for 36h: metolachlor: instantaneous $R_{S}=1.4 \mathrm{~L} / \mathrm{d}, K_{S W}=5,110 \mathrm{~L} / \mathrm{kg}$ and carbendazime: instantaneous $R_{S}=0.9 \mathrm{~L} / \mathrm{d}, K_{S W}=1,090 \mathrm{~L} / \mathrm{kg}$ B. Mixed rate control model: water boundary layersorbent controlled (Eq. 5). C. Residuals for the first-order model and D. for the mixed rate control model.

\subsubsection{Comparison of sampling rates $R_{S}$}

We found very high sampling rates $R_{S}$ at the beginning of exposure after $1 \mathrm{~h}$ of 0.35 to $3.5 \mathrm{~L} / \mathrm{d}$ (Table 1 ). $R_{S}$ were calculated for an exposure duration of $24 \mathrm{~h}$ with Eq. 3 to allow a comparison of equivalent $R_{S}$ with a previous study with SDB-RPS disks by Vermeirssen et al. (2013). For nine comparable 
contaminants in Vermeirssen et al. (2013) - assessed at velocities of $\mathrm{v}=0.08$ to $0.14 \mathrm{~m} / \mathrm{s}$ in river water our $R_{S}$ are on average higher by a factor of 1.9. The observed high sampling rates $R s$ facilitate accumulation and measurement of the contaminants on passive samplers during short stormwater events. The higher $R_{S}$ are attributed to the higher flow velocity (Vermeirssen et al. 2008; Booij and Chen 2018) in the flow channel experiments $(0.75-0.85 \mathrm{~m} / \mathrm{s})$, which we deliberately chose to represent realistic velocities in sewers. In two cases (2.4-D and mecoprop) a higher initial uptake was observed in Experiment II than in Experiment I, although the average water concentrations were similar (Figure SI 6). This indicates the variability of $R_{S}$, which we hypothesize to be due to competition for adsorption due to different wastewater matrices in the two experiments. Moreover, both of the contaminants have low $\log \mathrm{D}_{\mathrm{ow}}$ values. The wastewater-groundwater mixture in the present study may well have a higher competition for adsorption sites with other contaminants and dissolved organic carbon than in river or tap water matrix (Górecki et al. 1999; Bauerlein et al. 2012). The effect of ionic strength and different water matrices on accumulation of contaminants will need further investigation.

We found higher $R_{S}$ for higher $\operatorname{logKow}$ ( $\operatorname{logDow}$ in case of speciation, Table 1) values (slope $=0.18 \mathrm{~L} / \mathrm{d}$, intercept $=0.22 \mathrm{~L} / \mathrm{d}, \mathrm{R}^{2}=0.85$, Figure SI 7). Some previous studies also indicated a linear relationship of $R_{S}$ with the contaminant properties described by $\log \mathrm{K}_{\mathrm{OW}}$ or $\log \mathrm{D}_{\mathrm{Ow}}$ for SDB-RPS (Stephens et al. 2005; Vermeirssen et al. 2013). Others report only a poor correlation for SDB-RPS disks (Gunold et al. 2008; Shaw et al. 2009) or a curve linear relationship for POCIS (Mazzella et al. 2007; McLeod et al. 2007). These differences in previous studies highlight that several factors apart from hydrophobicity influence $R_{S}$. 


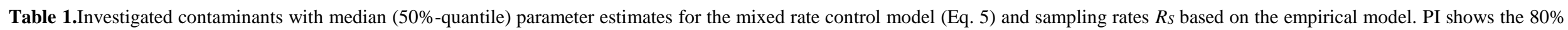
prediction interval (PI). The contaminant's Chemical Abstracts Service (CAS) number as well as the $80 \%$-interquantiles of the parameter values are given in Table SI 2

\begin{tabular}{|c|c|c|c|c|c|c|c|c|c|c|c|c|}
\hline \multirow[t]{2}{*}{ Contaminant name } & \multirow[t]{2}{*}{ Type } & \multirow{2}{*}{$\begin{array}{c}\operatorname{logKow}^{\mathrm{a}} / \\
\operatorname{logDow}^{\mathrm{b}} \\
\mathrm{pH}=8 \\
\end{array}$} & \multicolumn{3}{|c|}{$\begin{array}{c}\text { Mixed rate control model } \\
\text { solely fitted for Ex. II } \\
\text { (Eq. 5) }\end{array}$} & \multicolumn{3}{|c|}{$\begin{array}{c}\text { Mixed rate control model } \\
\text { fitted for Ex. I and II } \\
\text { (Eq. 5) }\end{array}$} & \multicolumn{2}{|c|}{ Sampling rates $R_{s}{ }^{\mathrm{c}}$} & \multirow{2}{*}{$\begin{array}{c}\text { Acute EQS }^{\mathbf{d}} \\
\text { ng/L }\end{array}$} & \multirow{2}{*}{$\begin{array}{c}\text { Exposure to } \\
\text { detect EQS } \\
\text { min } \\
\end{array}$} \\
\hline & & & $\begin{array}{c}\text { k } \\
\mathrm{L} / \mathrm{kg} / \mathrm{h}^{\mathrm{n}}\end{array}$ & $\begin{array}{l}\mathbf{n} \\
- \\
\end{array}$ & $\begin{array}{c}\text { PI } \\
\text { ng/disk } \\
\end{array}$ & $\begin{array}{c}\mathrm{k} \\
\mathrm{L} / \mathrm{kg} / \mathrm{h}^{\mathrm{n}} \\
\end{array}$ & $\begin{array}{l}\mathbf{n} \\
- \\
\end{array}$ & $\begin{array}{c}\text { PI } \\
\text { ng/disk } \\
\end{array}$ & $\begin{array}{c}\mathbf{R}_{S_{1} 1 \mathrm{~h}} \\
\mathbf{L} / \mathbf{d}\end{array}$ & $\begin{array}{c}\mathbf{R}_{S \_24 h} \\
\text { L/d }\end{array}$ & & \\
\hline $2-4-\mathrm{D}$ & pesticide & -1.0 & 60 & 0.52 & 17 & 40 & 0.63 & 22 & 0.35 & 0.10 & 4,000 & $<1.0$ \\
\hline 1-3-BTH-2-sulfonate* & other*** & -0.4 & 40 & 0.56 & 6 & 50 & 0.52 & 9 & 0.39 & 0.08 & - & - \\
\hline benzotriazole ${ }^{*}$ & other $* * *$ & 1.2 & 240 & 0.43 & 69 & 140 & 0.59 & 96 & 1.10 & 0.30 & 158,000 & $<1.0$ \\
\hline carbamazepine ${ }^{* *}$ & pharmaceutical & 2.8 & 200 & 0.71 & 95 & 110 & 0.88 & 153 & 0.89 & 0.61 & $2,000,000$ & $<1.0$ \\
\hline carbendazim & biocide & 1.8 & 250 & 0.55 & 39 & 220 & 0.6 & 52 & 1.70 & 0.48 & 700 & $<1.0$ \\
\hline clarithromycin $^{* *}$ & pharmaceutical & 2.7 & 150 & 0.68 & 43 & 140 & 0.72 & 40 & 1.10 & 0.44 & 190 & 7.6 \\
\hline diazinon & pesticide & 4.2 & 580 & 0.56 & 59 & 450 & 0.63 & 90 & 3.6 & 1.1 & 20 & 6.0 \\
\hline diclofenac & pharmaceutical & 0.9 & 180 & 0.59 & 40 & 120 & 0.72 & 74 & 0.95 & 0.38 & 50 & 23 \\
\hline diuron $^{* *}$ & biocide & 2.5 & 290 & 0.65 & 44 & 240 & 0.7 & 67 & 1.9 & 0.73 & 250 & 2.3 \\
\hline $\mathrm{MCPA}^{*}$ & pesticide & -1.1 & 50 & 0.59 & 9 & 50 & 0.61 & 8 & 0.42 & 0.12 & 6,400 & $<1.0$ \\
\hline mecoprop & pesticide & -0.5 & 100 & 0.53 & 11 & 70 & 0.63 & 25 & 0.59 & 0.18 & 190,000 & $<1.0$ \\
\hline metolachlor & pesticide & 3.5 & 310 & 0.7 & 33 & 240 & 0.78 & 84 & 1. 9 & 0.92 & 3,3000 & $<1.0$ \\
\hline terbutryn & pesticide & 2.9 & 400 & 0.66 & 65 & 320 & 0.72 & 102 & 2.6 & 1.10 & 340 & $<1.0$ \\
\hline
\end{tabular}

${ }^{a} \operatorname{logKow}$ were taken from JChem for Excel, Version 18.8.0.253 (ChemAxon 2018). ${ }^{\mathrm{b}}$ Distribution coefficients are normalized to the fraction of the neutral species at $\mathrm{pH}=8$ according to JChem, ${ }^{\mathrm{c}}$ Sampling rates (Eq. 3) for $1 \mathrm{~h}$ and $24 \mathrm{~h}$ exposure duration, based on mixed rate control model (Eq. 6) and model parameter estimates for both Experiment I and II. ${ }^{\mathrm{d} A c u t e}$ environmental quality

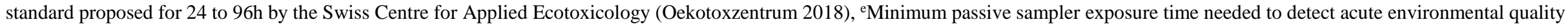
standards (EQS) based on Eq. 5 and highest reported limit of quantification (LOQ, Table 4.2), *For these contaminants outliers were removed for parameter estimation by visual inspection (grey points in Figure SI 6), ${ }^{* *}$ The Mixed rate control model assumes constant water concentration, which was not the case for diazinon, clarithromycin and carbamazepine, leading to higher uncertainty in parameter estimates (Figure SI 6), ***1-3-benzothiazole-2-sufonate: industrial chemical (e.g. street runoff), benzotriazole: corrosion inhibitor 


\subsection{Field study: comparability of passive and composite water samples}

We evaluated two aspects in the field study: i) the quantified TWA concentration estimate based on parameter estimates for calibration Experiment I and II (Eq. 5) and ii) the semi-quantitative information, i.e. categorical assessment of lower or higher than LOQ and lower or higher than EQS (environmental quality standard).

\subsubsection{TWA concentration estimate}

The analysis of the comparability of the TWA concentration estimates was conducted for a subset of the data, where values for both passive and composite water samples are higher than LOQ (45\% of the data set). The ratio of passive sampling $C_{P S}$ (based on the mixed rate model, Eq. 5) to composite water sampling $\mathrm{C}_{\text {Comp.Sample }}$ for all contaminants showed that the TWA concentration estimate with passive samplers is higher by a factor 1.5 (mean), with a range of 0.4 to 3.1 ( $80 \%$-interquantile, Figure $4 \mathrm{~A})$. The ratios $C_{P S} / \mathrm{C}_{\text {Comp.Sample }}$ are equally distributed over the whole concentration range with a median of 0.99 . In addition, no systematic deviations are visible in Figure 4A for the three sampled locations 1-3, although different environmental conditions may have been prevailing at the different locations (section 3.2).

Studying the sampled contaminants in more detail, contaminants occurring in wastewater dry-weather flow (benzotriazole, carbamazepine, clarithromycin, diclofenac) are overestimated Figure 4B). For location 1, these overestimation of the wastewater based contaminants is most prominent and attributed to the sampler installation setup directly in the sewer channel, where passive samplers might occasionally have been exposed to wastewater during dry-weather conditions when the auto-sampler did not collect water. However, for carbendazim, mecoprop and terbutryn we found considerably smaller concentration estimates with passive samplers. Hence, this shows that the laboratory based calibration parameters, which were used for concentration estimation, could be improved by in-situ calibration or by correcting the concentration estimates with the field validation.

We found a slightly higher variability for our field derived TWA concentrations estimates for some contaminants (terbutryn, carbendazim) than previous studies. Petrie et al. (2016) found for the in-situ calibration in wastewater effluent an agreement within a factor 2 for most contaminants, although passive samplers resulted in lower TWA concentrations than composite water samples. Also Skodova et al. (2016) reported an agreement within a factor 2 but with a tendency to higher concentration values for passive samplers. Similarly, Birch et al. (2013) reported higher concentration values for heavy metals monitored with flow-through passive samplers than in water samples. Our field monitoring study is based on laboratory calibration data used for real field conditions with varying environmental concentrations, low concentrations, thus potentially leading to higher uncertainties in the estimate $C_{P S}$. In addition, the composite water sampling itself is subjected to errors and might not fully represent the true TWA concentration (Mutzner et al. 2019). Because the sampling resolution was high with a sample every 5minutes, we attribute this uncertainty mainly to variability in sampling (clogging, uneven pumping of auto-sampler), sample transport and storage. 


\section{A}

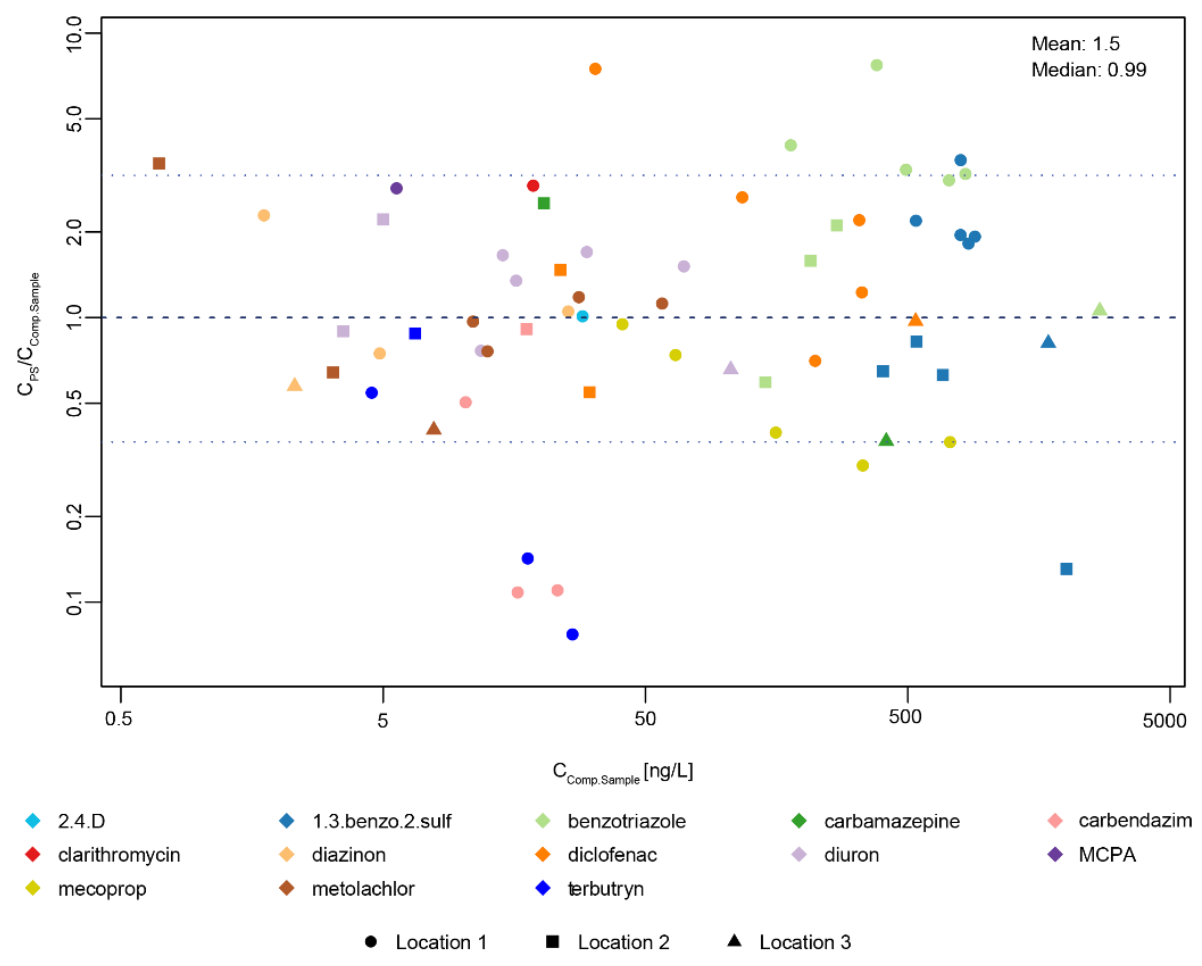

\section{B}

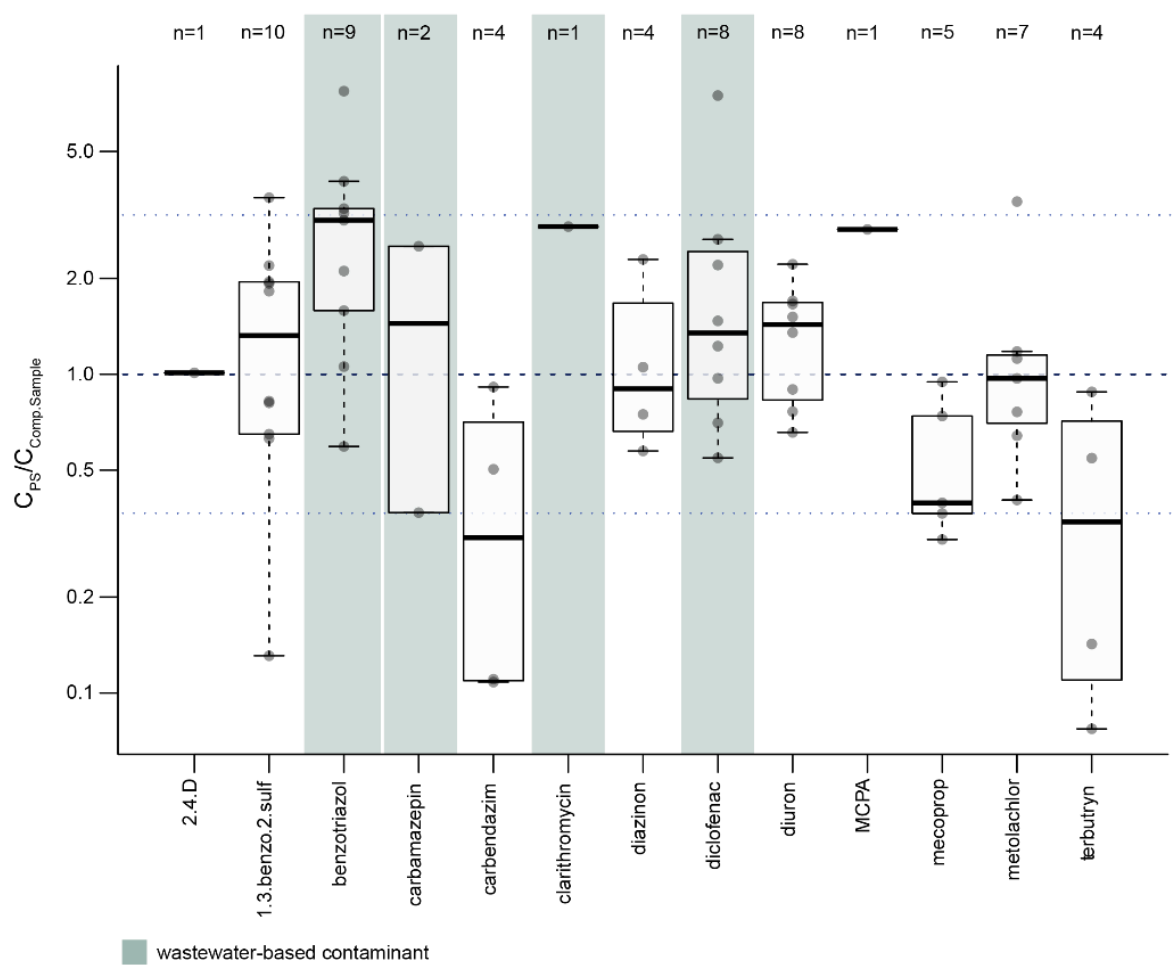

Figure 4.A. Ratio of TWA water concentration $\mathrm{C}_{\mathrm{PS}}$ based on mean of replicates of passive sampler (Eq. 5) to TWA composite water samples $\mathrm{C}_{\text {Comp.Sample }}$ for 13 contaminants and ten rain events. Dashed line indicates a ratio of one, dotted lines: $10 \%$ and $90 \%$ quantiles. B. Water concentration estimate for passive samplers relative to TWA concentration for individual contaminants. The dashed line shows a ratio of 1 for passive sampler to composite water sample TWA concentration estimate, dotted lines: 10\% and 90\% quantiles over all contaminants (as shown in Figure 4A). Boxplot: The whiskers show 1.5 times the interquantile range, points indicate outliers, and the solid bold line is the median. Number of detections are given by $n$. 


\subsubsection{Semi-quantitative information content}

Our results showed that higher concentrations, evaluated in comparison to EQS, were detected by passive samplers and composite water samples alike in 6 of 9 cases ( 2 only composite water samples > EQS, 1 only passive sampler > EQS; Figure 4.5). Based on the calibration experiments, event durations between $<1 \mathrm{~min}$ (carbamazepine) and $23 \mathrm{~min}$ (diclofenac) are needed to ensure detection of contaminant concentrations above EQS with passive samplers (Table 1). Hence, all events were long enough to detect concentrations above EQS. Nevertheless, passive samplers detected less contaminants $(<\mathrm{LOQ}$, Table 2) than measured in composite water samples for all contaminants except benzotriazole, which was only quantifiable in one event with passive sampler (location 2, 04.08.2016). From all measured samples and contaminants $22 \%$ were below the limit of quantification for the composite water samples and $48 \%$ for the passive samplers (mean of replicates).

Table 2. Measured concentration ranges and limit of quantifications (LOQ) for composite water samples and passive samplers in the field study (10 events, 3 locations).

\begin{tabular}{|c|c|c|c|c|c|c|}
\hline \multirow[t]{2}{*}{$\begin{array}{l}\text { Contaminant } \\
\text { name }\end{array}$} & $\begin{array}{c}\text { LOQ } \\
\text { water } \\
\text { samples }^{\mathrm{a}}\end{array}$ & $\begin{array}{c}\text { LOQ } \\
\text { passive } \\
\text { sampler }^{\mathrm{a}}\end{array}$ & $\begin{array}{c}\text { Concentration } \\
\text { range water } \\
\text { sample } \\
\text { CComp.Sample } \\
\text { (min and max) }\end{array}$ & $\begin{array}{c}\text { Mass on passive } \\
\text { sampler disk } \\
\text { range } M_{P S} \\
\text { (min and max) }\end{array}$ & $\begin{array}{c}\text { Concentration } \\
\text { range passive } \\
\text { sampler }^{\mathbf{b}} \\
\text { CPS } \\
\text { (min and max) }\end{array}$ & $\begin{array}{c}\text { Median } \\
\text { variability } \\
\text { passive } \\
\text { sampler } \\
\text { replicates }\end{array}$ \\
\hline & ng/L & ng/disk & ng/L & ng/disk & ng/L & $\%$ \\
\hline $2.4-\mathrm{D}$ & $4.7-5$ & 1.9 & $27-150$ & 2 & 29 & - \\
\hline $\begin{array}{l}\text { 1.3-benzothiazole- } \\
2 \text {-sulfonate }\end{array}$ & $8-13$ & $1-2$ & $400-2000$ & $3.6-220$ & $190-3,700$ & 46 \\
\hline benzotriazole & $1-55$ & $1-2$ & $140-2700$ & $3.2-680$ & $74-3,000$ & 24 \\
\hline carbamazepine & $1-1.4$ & $0.3-2$ & $2.7-410$ & $1.7-39$ & $49-170$ & 14 \\
\hline carbendazim & $0.6-1$ & $0.3-0.5$ & $10-47$ & $0.5-8$ & $1.8-23$ & 15 \\
\hline clarithromycin & $0.5-1$ & $1.8-2$ & $1.2-220$ & 14 & $54-55$ & 2.8 \\
\hline diazinon & $0.6-1$ & $0.3-0.7$ & $1.6-25$ & $0.6-21$ & $1.1-30$ & 13 \\
\hline diclofenac & $1-2$ & $0.7-1$ & $2.4-540$ & $0.9-200$ & $13-860$ & 22 \\
\hline diuron & $1.5-2$ & $0.6-2$ & $1.5-110$ & $1.5-49$ & $3-110$ & 16 \\
\hline MCPA & $5.5-40$ & $0.8-1.5$ & $5.6-130$ & $1.5-1.7$ & $15-17$ & 11 \\
\hline mecoprop & $2.4-2.6$ & $0.7-2$ & $12-1400$ & $2.1-26$ & $18-540$ & 38 \\
\hline metolachlor & $0.6-1.8$ & $0.6-1$ & $0.7-58$ & $0.8-35$ & $1.5-72$ & 37 \\
\hline terbutryn & $0.6-1.8$ & 1.4 & $0.6-26$ & $1.6-5$ & $2-7.1$ & 1.7 \\
\hline
\end{tabular}

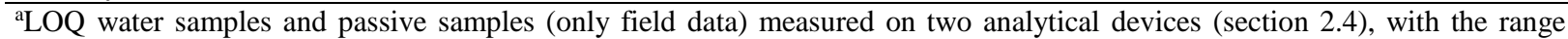

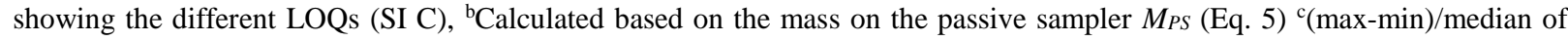
passive sampler replicates per event

The event on the 10.07.17, with the shortest exposure duration of $1 \mathrm{~h}$ shows the highest numbers <LOQ in passive samplers compared to composite water samples (Figure 5). Also for location 3 (event 28.06.2017) six contaminants are <LOQ while the composite water sample concentrations are not close to LOQ (e.g. 1,400ng/L in the extreme case of mecorpop, 28.06.2017, location 3). Based on the observed concentrations and the exposure duration of $8 \mathrm{~h}$, there should be detectable mass on the passive samplers. The samplers could have been covered by paper during part of the event, thus showing the importance of selection of an installation point without risk of clogging of the samplers (Figure SI 9).

Overall, the most critical factors for passive sampling of sewers and sewer overflows are i) a short event duration combined with ii) very low contaminant concentrations (Figure SI 13) and iii) clogging of the passive sampler (Figure SI 9). Thus, the semi-quantitative information gain with respect to presence of a contaminant is smaller for passive samplers in case of low concentrations in combination with a short event duration. However, this case can also be argued to be of lower eco-toxicological relevance. 


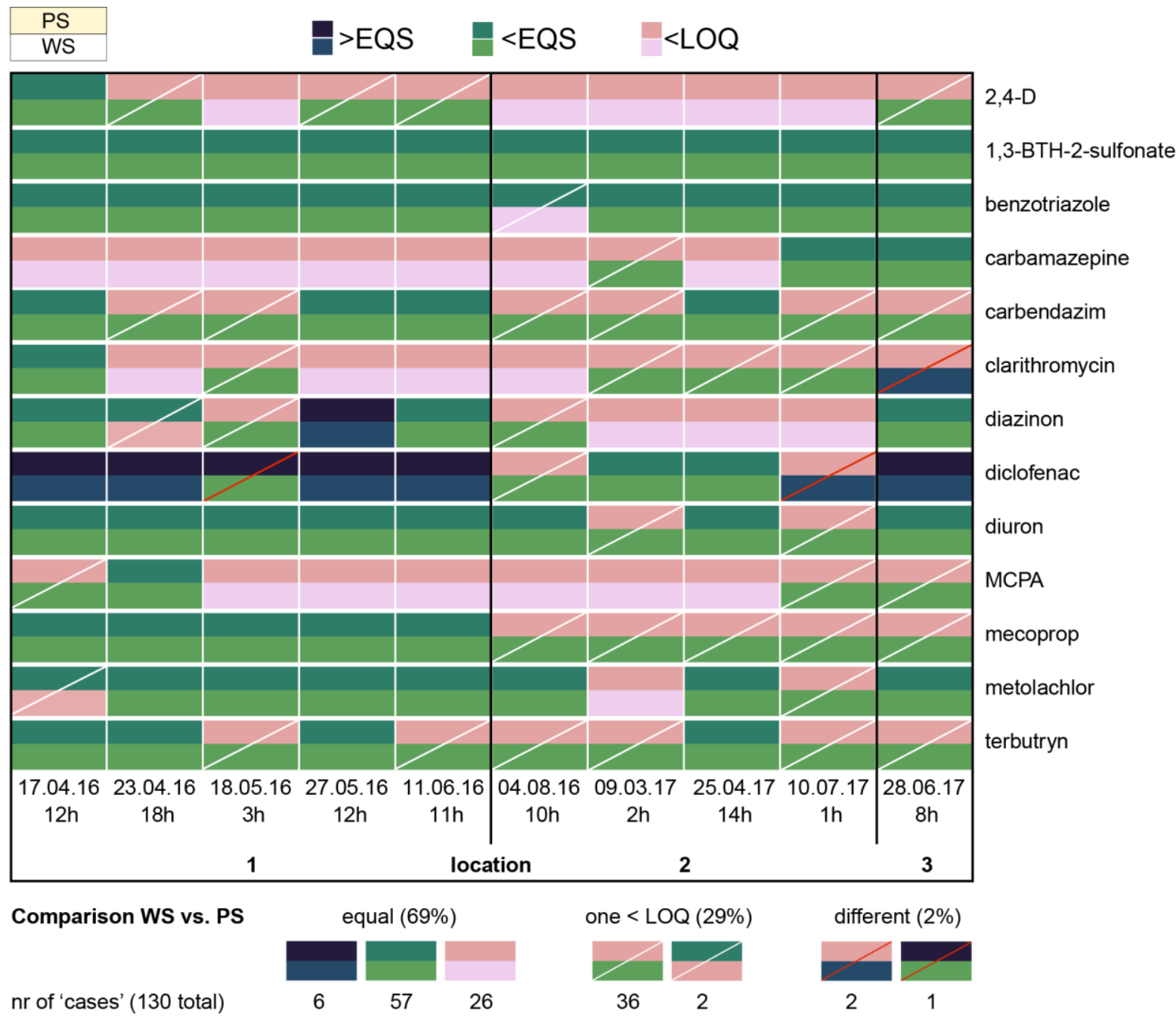

Figure 5. Semi-quantitative information content of passive samplers PS (average of replicates) compared with composite water samples ( $\mathrm{C}_{\text {Comp.Sample, }}$ WS) by grouping into $<\mathrm{LOQ}$ (pink), $>$ LOQ and $<\mathrm{EQS}$ (green), $>\mathrm{EQS}$ (blue) for a total of 10 events at three locations 1,2 and 3. Upper row per contaminant $=$ PS, lower row per contaminant $=$ WS. White diagonals indicate assignment of different categories by PS and WS, red diagonals indicate different conclusion related to exceedance of EQS. The event duration in hours is shown below the event dates.

\subsection{Recommendations for the application of passive samplers in sewers}

Number of replicate passive samplers. None of the monitored events results in systematic deviations of the replicates for all contaminants, showing that the replicate passive sampler were subject to the same environmental conditions at the sampling locations (number of replicates per event in Table SI 3). The median variability of the field replicates ranges from $1.7 \%$ for terbutryn to $46 \%$ for 1.3 benzothiazole-2-sulfonate (Table 2), indicating that the replicates are concentration and contaminant dependent as well as the potential variability of field monitoring with passive samplers. The number of replicates depends on specific measurement goals, and we conclude here that at least two replicate passive samplers should be used for sewer monitoring if TWA concentration estimates or comparison with EQS is required.

Event durations. Very short event durations in combinations with low concentrations lead to nonquantifiable mass on passive samplers. Minimum required exposure times can be estimated with Eq. 3 based on expected TWA concentrations, the foreseen limits of quantification (Table 2) and the sampling rates $R_{S}$ given in Table 1. A first estimation of relevant exposure durations is given in Table 1, which provides the exposure time to detect a contaminant present at its acute toxicity EQS (based on 24 to $48 \mathrm{~h}$ ). 
The longest necessary exposure duration is 23 min for diclofenac, due to its low EQS value of $50 \mathrm{ng} / \mathrm{L}$. Additionally, the investigated sampler setup with uncovered SDB-RPS disks is suitable for the monitoring of short duration exposure not significantly higher than $36 \mathrm{~h}$.

Installation considerations. We looked at three different installation setups in location 1 to 3 (section 3.2 and Figure SI 9-12). In order to sample pollution events (e.g. sewer overflows), the aim is to install the samplers in advance (location 1 and 2). Hence, the installation setup needs to ensure that samplers are wetted at all times before the occurrence of the storm event. We installed the new samplers directly when we collected the samplers from the last event, thus the new samplers were installed days to a maximum of three weeks in advance. Evaporation was location and season dependent and regular checks at new locations had to be done to confirm that the samplers were still covered in nanopure. However, we observed fast drying of the samplers in location 3 during late summer month due to evaporation, hence the samplers were covered with a floatable protection. Biofilm growth was not observed before or after exposure. We achieved wetting via horizontal installation of a sampler holder design incorporating a small water reservoir of a $5 \mathrm{~mm}$ depth (Figure 4.2, Figure SI 8-10). This system only works for locations with sufficient humidity and no direct sunlight. Horizontal installation of the holder on overflow weirs is relatively straightforward (Figure SI 10). However, horizontal installation in sewer pipes is challenging as the sampler might be overflown during high water levels without occurrence of a rain event and, we also observed clogging in some cases (Figure SI 9). Clogging could be avoided by a sampler holder that is prolonged in direction upstream or by installation on the overflow weir, where less solid material accumulates.

Application cases. We find that passive sampling can be used to i) determine the occurrence of contaminants during storm events in sewers and ii) estimate the TWA concentration in the water phase. However, it needs to be considered that we found a higher rate of values below the limit of quantification with passive samplers attributed to sampler clogging or short event durations. Thus, it is recommended to sample more than one event to cover potential inter-event variability and reduce sampling uncertainty. Nevertheless, passive samplers give similar categorical information for concentrations above EQS. Moreover, we find reasonable TWA concentration estimates in case of elevated concentrations and/or 'sufficient' event durations (Table 4.2), which are also the events expected to be most environmentally relevant. Based on calibration experiments, we suggest a semiempirical mixed rate control model and report model parameters for typical sewer conditions. These parameters can directly be used for similar cases (Table 4.1). If your field conditions deviate substantially from ours, in-situ calibrations are needed to adjust model parameters. In addition, we report confidence intervals for the calibration parameters, which allows the calculation of uncertainty ranges of the calculated TWA concentration (Table SI 2 for quantiles or model parameters). 


\section{Conclusions}

We conclude the following for the application of passive samplers in short, highly dynamic sewer overflows:

- Typical remote sewer locations can be sampled in a cost- and time-effective way with passive samplers, as field deployment and sample handling is easier compared to composite water sampling.

- High sampling rates lead to fast accumulation, which makes the sampler suitable for monitoring of TWA concentrations in short events $(<36 \mathrm{~h})$.

- We observe a fast initial uptake, which indicates that uptake on the passive sampler is not limited by the water boundary layer. We, therefore, suggest a semi-empirical mixed rate control model to represent kinetics for short exposures and provide model parameters, which can be directly used for studies with similar conditions.

- Passive samplers are suitable to identify locations with potentially critical concentrations >EQS, where further investigations are warranted, or vice versa uncritical locations where concentrations normally do not exceed EQS.

- We find that TWA water concentration estimates with passive samplers are within a factor of 0.4 to 3.1 (80\% confidence interval) in comparison to composite water samples. Hence, the use of upper limit TWA concentration estimates is recommended for compliance checking with EQS.

- We observed variable sampling rates which could be due to competition for adsorption sites. The effect of wastewater matrix on the accumulation kinetics requires further research to better understand accumulation of polar organic contaminants on passive samplers.

\section{Acknowledgements}

The authors thank the Swiss Federal Office for the Environment for funding (contract nr. 00.0102.PZ/P401-1414). We are very thankful for the support during field work (Simon Dicht, Eawag, SWW) and for chemical analyses (Philipp Longree, Eawag, Uchem). We gratefully acknowledge the contribution of Christoph Bohren, who did his master thesis on the topic and performed Experiment III and IV. 


\section{References}

Alvarez, D.A., Stackelberg, P.E., Petty, J.D., Huckins, J.N., Furlong, E.T., Zaugg, S.D. and Meyer, M.T. (2005) Comparison of a novel passive sampler to standard water-column sampling for organic contaminants associated with wastewater effluents entering a New Jersey stream. Chemosphere 61(5), 610-622.

Bahlmann, A., Brack, W., Schneider, R.J. and Krauss, M. (2014) Carbamazepine and its metabolites in wastewater: Analytical pitfalls and occurrence in Germany and Portugal. Water Research 57, 104-114.

Bauerlein, P.S., Ter Laak, T.L., Hofman-Caris, R.C., de Voogt, P. and Droge, S.T. (2012) Removal of charged micropollutants from water by ion-exchange polymers -- effects of competing electrolytes. Water Research 46(16), 5009-5018.

Baz-Lomba, J.A., Harman, C., Reid, M. and Thomas, K.V. (2017) Passive sampling of wastewater as a tool for the long-term monitoring of community exposure: Illicit and prescription drug trends as a proof of concept. Water Research 121, 221-230.

Becouze-Lareure, C., Dembélé, A., Coquery, M., Cren-Olivé, C., Barillon, B. and Bertrand-Krajewski, J.L. (2015) Source characterisation and loads of metals and pesticides in urban wet weather discharges. Urban Water Journal 13(6), 1-18.

Belles, A., Pardon, P. and Budzinski, H. (2014) Development of an adapted version of polar organic chemical integrative samplers (POCIS-Nylon). Analytical and Bioanalytical Chemistry 406(4), 1099-1110.

Birch, H., Sharma, A.K., Vezzaro, L., Lützhøft, H.C.H. and Mikkelsen, P.S. (2013) Velocity dependent passive sampling for monitoring of micropollutants in dynamic stormwater discharges. Environmental Science \& Technology 47(22), 12958-12965.

Booij, K. and Chen, S. (2018) Review of atrazine sampling by polar organic chemical integrative samplers and Chemcatcher. Environmental Toxicology and Chemistry 37(7), 1786-1798.

Booij, K., Vrana, B. and Huckins, J.N. (2007) Chapter 7: Theory, modelling and calibration of passive samplers used in water monitoring., Elsevier, Amsterdam.

Brudler, S., Rygaard, M., Arnbjerg-Nielsen, K., Hauschild, M.Z., Ammitsoe, C. and Vezzaro, L. (2019) Pollution levels of stormwater discharges and resulting environmental impacts. The Science of the total environment $663,754-763$.

Burant, A., Selbig, W., Furlong, E.T. and Higgins, C.P. (2018) Trace organic contaminants in urban runoff: Associations with urban land-use. Environmental pollution 242(Pt B), 2068-2077.

ChemAxon (2018) JChem for Excel, version 18.8.0.253.

Crank, J. (1975) The mathematics of diffusion / by J. Crank, Clarendon Press, Oxford [England].

Fairbairn, D.J., Elliott, S.M., Kiesling, R.L., Schoenfuss, H.L., Ferrey, M.L. and Westerhoff, B.M. (2018) Contaminants of emerging concern in urban stormwater: Spatiotemporal patterns and removal by iron-enhanced sand filters (IESFs). Water Research 145, 332-345.

Fauvelle, V., Mazzella, N., Belles, A., Moreira, A., Allan, I.J. and Budzinski, H. (2014) Optimization of the polar organic chemical integrative sampler for the sampling of acidic and polar herbicides. Analytical and Bioanalytical Chemistry 406(13), 3191-3199. 
Górecki, T., Yu, X. and Pawliszyn, J. (1999) Theory of analyte extraction by selected porous polymer SPME fibres. Analyst 124(5), 643-649.

Green, C.E. and Abraham, M.H. (2000) Investigation into the effects of temperature and stirring rate on the solid-phase extraction of diuron from water using a C18 extraction disk. Journal of Chromatography A 885(1), 41-49.

Gunold, R., Schäfer, R.B., Paschke, A., Schüürmann, G. and Liess, M. (2008) Calibration of the Chemcatcher ${ }^{\circledR}$ passive sampler for monitoring selected polar and semi-polar pesticides in surface water. Environmental pollution 155(1), 52-60.

Harman, C., Reid, M. and Thomas, K.V. (2011) In Situ Calibration of a Passive Sampling Device for Selected Illicit Drugs and Their Metabolites in Wastewater, And Subsequent Year-Long Assessment of Community Drug Usage. Environmental Science \& Technology 45(13), 56765682.

Huckins, J.N., Petty, J.D. and Booij, K. (2006) Monitors of Organic Chemicals in the Environment. Sempipermeable Membrane Devices., Springer, USA.

Huntscha, S., Singer, H.P., McArdell, C.S., Frank, C.E. and Hollender, J. (2012) Multiresidue analysis of 88 polar organic micropollutants in ground, surface and wastewater using online mixed-bed multilayer solid-phase extraction coupled to high performance liquid chromatography-tandem mass spectrometry. Journal of Chromatography A 1268, 74-83.

Kingston, J.K., Greenwood, R., Mills, G.A., Morrison, G.M. and Persson, L.B. (2000) Development of a novel passive sampling system for the time-averaged measurement of a range of organic pollutants in aquatic environments. Journal of Environmental Monitoring 2(5), 487-495.

Launay, M.A., Dittmer, U. and Steinmetz, H. (2016) Organic micropollutants discharged by combined sewer overflows - Characterisation of pollutant sources and stormwater-related processes. Water Research 104, 82-92.

Mazzella, N., Dubernet, J.-F. and Delmas, F. (2007) Determination of kinetic and equilibrium regimes in the operation of polar organic chemical integrative samplers: Application to the passive sampling of the polar herbicides in aquatic environments. Journal of Chromatography A $1154(1-2), 42-51$.

McLeod, P.B., van den Heuvel-Greve, M.J., Luoma, S.N. and Luthy, R.G. (2007) Biological uptake of polychlorinated biphenyls by Macoma balthica from sediment amended with activated carbon. Environmental Toxicology and Chemistry 26(5), 980-987.

Miège, C., Mazzella, N., Allan, I., Dulio, V., Smedes, F., Tixier, C., Vermeirssen, E., Brant, J., O'Toole, S., Budzinski, H., Ghestem, J.P., Staub, P.F., Lardy-Fontan, S., Gonzalez, J.L., Coquery, M. and Vrana, B. (2015) Position paper on passive sampling techniques for the monitoring of contaminants in the aquatic environment - Achievements to date and perspectives. Trends in Environmental Analytical Chemistry 8, 20-26.

Mutzner, L., Staufer, P. and Ort, C. (2016) Model-based screening for critical wet-weather discharges related to micropollutants from urban areas. Water Research 104, 547-557.

Mutzner, L., Vermeirssen, E.L.M. and Ort, C. (2019) Passive samplers in sewers and rivers with highly fluctuating micropollutant concentrations - Better than we thought. Journal of Hazardous Materials 361, 312-320.

Mutzner, L., Vermeirssen, E. L. M., Mangold, S., Maurer, M., Scheidegger, A., Singer, H., Ort, C., 
Data for: Passive samplers to quantify micropollutants in sewer overflows: accumulation behaviour and field validation for short pollution events (2019). http://doi.org/10.25678/0000CC)

Oekotoxzentrum (2018) Vorschlaege für akute und chronische Qualitaetskriterien für ausgewaehlte schweizrelevante Substanzen (Suggestet maximum allowable concentrations and annual averaged concentration of Enivironmental Quality Standards for Switzerland). http://www.oekotoxzentrum.ch/expertenservice/qualitaetskriterien/vorschlaege/index?clear_lang =1 Accessed: 2018-10-10 (Archived by WebCite® at http://www.webcitation.org/733uxUHJH ) $(10.10 .2018)$

Ort, C., Lawrence, M.G., Reungoat, J. and Mueller, J.F. (2010) Sampling for PPCPs in wastewater systems: Comparison of different sampling modes and optimization strategies. Environmental Science \& Technology 44(16), 6289-6296.

Petrie, B., Gravell, A., Mills, G.A., Youdan, J., Barden, R. and Kasprzyk-Hordern, B. (2016) In-situ calibration of a new Chemcatcher(R) configuration for the determination of polar organic micropollutants in wastewater effluent. Environmental Science \& Technology 50(17), 94699478.

R Core Team (2017) R: A language and environment for statistical computing., R Foundation for Statistical Computing, http://www.R-project.org, Vienna.

Rippy, M.A., Deletic, A., Black, J., Aryal, R., Lampard, J.L., Tang, J.Y., McCarthy, D., Kolotelo, P., Sidhu, J. and Gernjak, W. (2017) Pesticide occurrence and spatio-temporal variability in urban run-off across Australia. Water Research 115, 245-255.

Risch, E., Gasperi, J., Gromaire, M.C., Chebbo, G., Azimi, S., Rocher, V., Roux, P., Rosenbaum, R.K. and Sinfort, C. (2018) Impacts from urban water systems on receiving waters - How to account for severe wet-weather events in LCA? Water Research 128, 412-423.

Scheidegger, A. (2018) AdaptMCMC: Implementation of a Generic Adaptive Monte Carlo Markov Chain Sampler. R package version 1.3., https://CRAN.R-project.org/package=adaptMCMC.

Senta, I., Terzic, S. and Ahel, M. (2013) Occurrence and fate of dissolved and particulate antimicrobials in municipal wastewater treatment. Water Research 47(2), 705-714.

Shaw, M., Eaglesham, G. and Mueller, J.F. (2009) Uptake and release of polar compounds in SDB-RPS Empore disks; implications for their use as passive samplers. Chemosphere 75(1), 1-7.

Shaw, M. and Mueller, J.F. (2009) Time Integrative Passive Sampling: How Well Do Chemcatchers Integrate Fluctuating Pollutant Concentrations? Environmental Science \& Technology 43, 1443 1448 .

Singer, H., Jaus, S., Hanke, I., Lück, A., Hollender, J. and Alder, A.C. (2010) Determination of biocides and pesticides by on-line solid phase extraction coupled with mass spectrometry and their behaviour in wastewater and surface water. Environmental pollution 158(10), 3054-3064.

Skodova, A., Prokes, R., Simek, Z. and Vrana, B. (2016) In situ calibration of three passive samplers for the monitoring of steroid hormones in wastewater. Talanta 161, 405-412.

Soetaert, K., Petzoldt, T. and Woodrow Setzer, R. (2010) Solving Differential Equations in R: Package deSolve. , http://www.jstatsoft.org/v33/i09/

Stephens, B.S., Kapernick, A., Eaglesham, G. and Mueller, J. (2005) Aquatic passive sampling of herbicides on naked particle loaded membranes: accelerated measurement and empirical estimation of kinetic parameters. Environmental Science \& Technology 39(22), 8891-8897. 
Stephens, B.S., Kapernick, A.P., Eaglesham, G. and Mueller, J.F. (2009) Event monitoring of herbicides with naked and membrane-covered Empore disk integrative passive sampling devices. Marine Pollution Bulletin 58(8), 1116-1122.

Tran, H.N., You, S.J., Hosseini-Bandegharaei, A. and Chao, H.P. (2017) Mistakes and inconsistencies regarding adsorption of contaminants from aqueous solutions: A critical review. Water Research $120,88-116$.

Vermeirssen, E.L., Bramaz, N., Hollender, J., Singer, H. and Escher, B.I. (2009) Passive sampling combined with ecotoxicological and chemical analysis of pharmaceuticals and biocides evaluation of three Chemcatcher configurations. Water Research 43(4), 903-914.

Vermeirssen, E.L., Dietschweiler, C., Escher, B.I., van der Voet, J. and Hollender, J. (2013) Uptake and release kinetics of 22 polar organic chemicals in the Chemcatcher passive sampler. Analytical and Bioanalytical Chemistry 405(15), 5225-5236.

Vermeirssen, E.L.M., Asmin, J., Escher, B.I., Kwon, J.H., Steimen, I. and Hollender, J. (2008) The role of hydrodynamics, matrix and sampling duration in passive sampling of polar compounds with Empore $^{\mathrm{TM}}$ SDB-RPS disks. Journal of Environmental Monitoring 10(1), 119-128.

Vrana, B., Allan, I.J., Greenwood, R., Mills, G.A., Dominiak, E., Svensson, K., Knutsson, J. and Morrison, G. (2005) Passive sampling techniques for monitoring pollutants in water. TrAC Trends in Analytical Chemistry 24(10), 845-868.

Wicke, D., Caradot, N., Matzinger, A., Rouault, P., Heinzmann, B. and Kummelt, A. (2014) Monitoring of Micropollutant Loads in Urban Stormwater on City Scale Strategy and Realisation. 13th International Conference on Urban Drainage, Sarawak, Malaysia.

Zgheib, S., Moilleron, R. and Chebbo, G. (2011) Influence of the land use pattern on the concentrations and fluxes of priority pollutants in urban stormwater. Water Science \& Technology 64(7), 14501458 . 